\title{
Prevalence and risk factors of non-carious cervical lesions related to occupational exposure to acid mists
}

Rafael Aiello BOMFIM(a) Edgard CROSATO(b) Luiz Eugênio Nigro MAZZILLI(b) Antonio Carlos FRIAS(b)

(a) Universidade Federal de Mato Grosso do Sul - UFMS, School of Dentistry, Department of Community Dentistry, Campo Grande, MS, Brazil.

(b) Universidade de São Paulo - USP, School of Dentistry, Department of Community Dentistry, São Paulo, SP, Brazil.

Declaration of Interests: The authors certify that they have no commercial or associative interest that represents a conflict of interest in connection with the manuscript.

Corresponding Author:

Rafael Aiello Bomfim

E-mail: rafael.aiello@ufms.br

DOI: 10.1590/1807-3107BOR-2015.vol29.0085

Submitted: Oct 21, 2014

Accepted for publication: Mar 10, 2015

Last revision: Jun 01, 2015
Abstract: This study evaluates the prevalence and risk factors of non-carious cervical lesions (NCCLs) in a Brazilian population of workers exposed and non-exposed to acid mists and chemical products. One hundred workers (46 exposed and 54 non-exposed) were evaluated in a Centro de Referência em Saúde do Trabalhador - CEREST (Worker's Health Reference Center). The workers responded to questionnaires regarding their personal information and about alcohol consumption and tobacco use. A clinical examination was conducted to evaluate the presence of NCCLs, according to WHO parameters. Statistical analyses were performed by unconditional logistic regression and multiple linear regression, with the critical level of $p<0.05$. NCCLs were significantly associated with age groups (18-34, 35-44, 45-68 years). The unconditional logistic regression showed that the presence of NCCLs was better explained by age group (OR $=4.04$; CI 95\% 1.77-9.22) and occupational exposure to acid mists and chemical products $(\mathrm{OR}=3.84$; CI 95\% 1.10-13.49), whereas the linear multiple regression revealed that NCCLs were better explained by years of smoking $(p=0.01)$ and age group ( $p=0.04)$. The prevalence of NCCLs in the study population was particularly high (76.84\%), and the risk factors for NCCLs were age, exposure to acid mists and smoking habit. Controlling risk factors through preventive and educative measures, allied to the use of personal protective equipment to prevent the occupational exposure to acid mists, may contribute to minimizing the prevalence of NCCLs.

Keywords: Occupational Health; Oral Health; Occupational Dentistry; Tooth Erosion.

\section{Introduction}

The oral cavity diseases and their risk factors involve an array of environmental, genetic, immunologic, and socio-behavioral factors, including education, oral hygiene habits, and access to dental care. Occupational or environmental exposure to acid mists is one of these factors, and it affects a large number of workers worldwide. ${ }^{1}$ A non-carious cervical lesion (NCCL) is a non-caries related loss of tooth structure at the cementoenamel junction. ${ }^{2}$ Multifactorial interactions are involved in its development, including erosion, abfraction and abrasion processes. ${ }^{3}$ It is well known that exposure to acid mist can lead to dental erosion, ${ }^{4,5} \mathrm{but}$ 
studies have not been adjusted for lifestyle behaviors such as alcohol consumption and tobacco use.

It is important to detect NCCLs as early as possible in order to prevent their progression, and it is critical to determine the risk factors involved in order to adopt preventive measures. ${ }^{6}$ Occupational and environmental exposure to acid mists may also irritate soft tissues, leading to other oral healthrelated effects such as periodontal changes and oral mucosa lesions. Furthermore, this chronic irritative process can increase the susceptibility to infections. Long-term contact with acid may promote salivary changes that favor the occurrence of periodontal disease. ${ }^{7}$ This, in turn, may cause gingival recession and root exposure, thus contributing to tissue abrasion from manual toothbrushing. ${ }^{8}$

Thus, the aim of this study was to evaluate the prevalence of and some of the risk factors involved in NCCLs in a Brazilian population of workers exposed and non-exposed to acid mists and chemical products.

\section{Methodology}

\section{Ethical aspects and sample selection}

The study protocol was approved by the local Research Ethics Committee at the Universidade de São Paulo - USP, School of Dentistry (process number 101-11 CAAE 0113.0.017.000-11). This was a cross-sectional study conducted at a Centro de Referência em Saúde do Trabalhador - CEREST (Worker's Health Reference Center), located in the city of Guarulhos, SP, whose coverage includes 10 other nearby cities. The aim of the investigation was explained to all workers, who were asked to sign a written informed consent form prior to participation in the study. Sample selection was conducted to allow for an assessment of the DMFT (decayed, missing and filled permanent teeth) index of this worker population, irrespective of the occurrence of edentulism. However, in order to conduct the logistic and linear regression analyses and determine the prevalence ratios of NCCLs, the edentulous individuals $(n=5)$ were excluded from the sample. This was done because, whether they belonged or not to the risk group, edentulous individuals would not express the formation of NCCLs.

\section{Sample size determination}

The sample size was determined using the formula described in Antunes and Peres, ${ }^{9}\left(\mathrm{n}=\mathrm{z}^{2} \times \mathrm{s}^{2} / \mathrm{d}^{2}\right)$, considering a $95 \%$ level of confidence $(z=1.96)$, which was used to determine the DMFT index, and then to establish the prevalence of NCCLs among the workers.

According to the data of national surveys, ${ }^{10}$ the standard deviation (SD) of the DMFT index in the southeast region of Brazil for the 35-44 years age group is $7.51(\mathrm{~s}=7.51)$. The error estimation ( $\mathrm{d}$ value) was measured for 1.5 unit of the DMFT ( 0.5 unit for each component of the index). By using these values in the formula, we have $\mathrm{n}=(1.96)^{2} \times(7.51)^{2} /(1.5)^{2}=96.25$, so the result was rounded up to a sample size of 100 workers.

We chose to use the 35-44 years age group in the sample size calculation because, according to national epidemiological surveys, this group is the one that best represents the "workers" category. The 65-74 years age group corresponds to elderly and retired individuals, and the preceding 15-19 years age group corresponds to adolescents.

\section{Data collection and oral examination}

Data collection and oral examination was conducted by one investigator (R.A.B.) previously trained to diagnose in the department of Community Dentistry, USP. Consistency was measured by the kappa index. We obtained a value of 0.7 during the first week, but the values were higher than 0.93 in the following weeks, thus indicating substantial agreement. For each 10 workers, one was re-examined to assess intra-examiner agreement.

The workers responded to questionnaires regarding personal and social demographic information (name, age, gender, educational level, marital status), occupational information (exposure to acid mists and chemical products, income), and reason for seeking assistance at the CEREST. In an interview with the investigator, the alcohol use disorders identification test (AUDIT) ${ }^{11}$ and the Fagerström Tolerance questionnaire ${ }^{12}$ were used to assess alcohol consumption and nicotine dependence.

The workers classified as exposed to acid mists and chemical products were those that had been working in electroplating and metallurgical plants, welders, 
cleaners, and those working in product recycling. Those non-exposed to acid mists were tailors, drivers, gardeners, masons, carpenters, musicians, cooks and those working in administrative services.

All workers were submitted to a clinical dental exam, which was performed on all teeth, including third molars (if present). The DMFT index was assessed in the examination, according to $\mathrm{WHO}$ criteria.

\section{Diagnostic criteria for NCCLs}

The diagnostic criteria for NCCLs were location in the cervical third of the tooth, no caries, wedge-shaped lesion with sharp edges, or C-shaped lesion with rounded edges.

\section{Statistical analyses}

Frequency distribution and cross tabulation tables were constructed using Microsoft Excel 2013 (Microsoft Inc., Redmond, USA), and the data was processed using the Statistical Package for the Social Sciences (version 17.0; SPSS Inc., Chicago, USA). Unconditional logistic regression was performed to explain the presence or absence of NCCLs, and linear multiple regression was performed to explain the number of lesions, with a confidence interval of $95 \%$.

The workers were divided into three age groups to allow a comparison with the data of the latest Brazilian national oral health survey. ${ }^{13}$

\section{Results}

One hundred workers were eligible to participate in this study. The age of the subjects ranged from 20 to 68 years old, with a mean age of 44.15 years (SD 10.30). Of the workers, $55 \%$ were males, $60 \%$ were married, $61 \%$ had not completed high school, 59\% earned less than 500 dollars per month, and $46 \%$ had been exposed to acid mists and chemical products, as shown in Table 1.

The mean DMFT index for the workers was 16.21 (SD 7.27), and it was significantly associated with age group. The mean number of NCCLs was 3.41 (SD 4.01), which corresponds to $19.44 \%$ (SD 22.80) of teeth with NCCLs, considering all teeth present in the mouth and excluding lost teeth. Of all workers analyzed, $76.84 \%$ had NCCLs. The number of NCCLs was significantly different among age groups, and increased with age in all age groups, as shown in Table 2. In the 35-44 years age group, the numbers of NCCLs in exposed workers was significantly higher compared to non-exposed workers $(p=0.01)$.

Fagerström questionnaire and AUDIT test scores were not associated with age groups according to the Kruskall-Wallis test $(\mathrm{p}=0.30$ and $\mathrm{p}=0.60$, respectively), as can be seen in Table 3 .

Table 4 shows that $31 \%$ were smokers, $23 \%$ were ex-smokers and $46 \%$ were non-smokers. Among smokers and ex-smokers, 22\% had smoked for less than 15 years and 32\%, for more than 15 years (Table 4).

In regard to alcohol use, 56\% had no drinking habit and $88 \%$ had a low dependence on alcohol use, as measured by the AUDIT test (score 0-7; Table 5).

The number and percentage of NCCLs were not associated with Fagerström dependence scores ( $p=0.32$ and $p=0.09$, respectively) but were associated with years of smoking $(p=0.0006$ and $p=0.0003)$, as shown in Table 6.

Table 1. Demographic and occupational characteristics of the study sample.

\begin{tabular}{|c|c|c|c|}
\hline \multicolumn{2}{|c|}{ Demographic Characteristics } & (n) & (\%) \\
\hline \multirow[t]{2}{*}{ Gender } & Male & 55 & 55 \\
\hline & Female & 45 & 45 \\
\hline \multirow[t]{4}{*}{ Marital status } & Single & 16 & 16 \\
\hline & Married & 60 & 60 \\
\hline & Divorced & 21 & 21 \\
\hline & Widow(er) & 3 & 3 \\
\hline \multirow[t]{5}{*}{ Schooling } & Literate & 21 & 21 \\
\hline & Elementary school & 27 & 27 \\
\hline & Middle school & 13 & 13 \\
\hline & High school & 38 & 38 \\
\hline & University & 1 & 1 \\
\hline \multicolumn{2}{|c|}{ Occupational Characteristics } & (n) & (\%) \\
\hline \multirow[t]{4}{*}{ Monthly income } & Under US\$ 500 & 59 & 59 \\
\hline & From US\$ 501 to 1,000 & 36 & 36 \\
\hline & From US\$ 1,001 to 1,500 & 3 & 3 \\
\hline & Above US\$1,500 & 2 & 2 \\
\hline \multirow[t]{2}{*}{ Occupational status } & Exposed to acid mists & 46 & 46 \\
\hline & Non-exposed to acid mists & 54 & 54 \\
\hline \multirow{2}{*}{$\begin{array}{l}\text { Reason for seeking } \\
\text { health center assistance }\end{array}$} & Repetitive strain injury & 66 & 66 \\
\hline & Work accident & 34 & 34 \\
\hline
\end{tabular}


Table 2. Mean DMFT and NCCLs values (SD) according to age group.

\begin{tabular}{|c|c|c|c|c|c|c|c|}
\hline \multirow{2}{*}{ Age Group } & \multicolumn{2}{|c|}{$18-34$ years } & \multicolumn{2}{|c|}{$35-44$ years } & \multicolumn{2}{|c|}{$45-68$ years } & \multirow{2}{*}{$p$} \\
\hline & Mean & SD & Mean & SD & Mean & SD & \\
\hline DMFT & 8.94 & 5.03 & 14.72 & 5.54 & 19.3 & 6.79 & $<0.0001^{*}$ \\
\hline $\mathrm{D}$ & 2.42 & 2.65 & 2.75 & 2.13 & 1.69 & 2.55 & $0.01^{* *}$ \\
\hline M & 2.21 & 2.39 & 6.1 & 5.01 & 13.55 & 8.5 & $<0.0001^{*}$ \\
\hline $\mathrm{F}$ & 4.15 & 3.61 & 5.75 & 4.57 & 3.46 & 4.07 & 0.06 \\
\hline Number of teeth & 28.21 & 2.32 & 23.34 & 5.43 & 16.19 & 9.26 & $<0.0001^{*}$ \\
\hline NCCLs & 1.42 & 2.38 & 2.72 & 3.28 & 4.51 & 3.76 & $0.0015^{* *}$ \\
\hline NCCLs (\%) & \multicolumn{2}{|c|}{$5.03 \%$} & \multicolumn{2}{|c|}{$12.54 \%$} & \multicolumn{2}{|c|}{$28.56 \%$} & $0.0001^{*}$ \\
\hline Free of NCCLs (\%) & $57.89 \%$ & $n=11$ & $27.60 \%$ & $\mathrm{n}=8$ & $6.38 \%$ & $\mathrm{n}=3$ & $0.0001^{*}$ \\
\hline NCCLs in exposed subjects & 2.5 & $\mathrm{n}=8$ & 4.06 & $\mathrm{n}=15$ & 4.08 & $n=23$ & $<0.001^{* *}$ \\
\hline NCCLs in non-exposed subjects & 0.63 & $n=11$ & 1.15 & $n=14$ & 4.86 & $n=29$ & $<0.001^{* *}$ \\
\hline Difference exposed $\mathrm{x}$ non-exposed & \multicolumn{2}{|c|}{$p=0.13$} & \multicolumn{2}{|c|}{$p=0.01$} & \multicolumn{2}{|c|}{$p=0.54$} & \\
\hline (n) & \multicolumn{2}{|c|}{19} & \multicolumn{2}{|c|}{29} & \multicolumn{2}{|c|}{52} & \\
\hline
\end{tabular}

Statistical analysis: One-way ANOVA (DMFT) and Kruskall-Wallis (DMFT).

* Statistical difference for the 3 age groups.

**Statistical difference for 2 age groups.

Alcohol consumption measured by the AUDIT test was not associated with NCCLs $(p>0.05)$ in any of the age groups.

The number of NCCLs was better explained by years of smoking $(p=0.01)$ and age group $(p=0.04)$, as revealed by multiple linear regression (Table 7).

Unconditional logistic regression analysis was used to explain the presence or absence of NCCLS. It showed that age group $(\mathrm{OR}=4.04$; CI 95\% 1.77-9.22) and occupational exposure to acid mists and chemical products $(\mathrm{OR}=3.84 ; \mathrm{CI} 95 \% 1.10-13.49)$ were associated with the presence of NCCLs, irrespective of smoking habit and alcohol consumption (Table 8).

\section{Discussion}

The prevalence of NCCLs in this study was high, namely $19.44 \%$ of all analyzed teeth in all age groups. The rate of those affected with at least one NCCL was $76.84 \%$ of the workers examined. Tuominen et al. ${ }^{4}$ found that $63.4 \%$ of workers exposed to acid fumes versus $37.7 \%$ of non-exposed workers had tooth surface loss. Suyama et al. ${ }^{14}$ found a dental erosion rate of $20 \%$ among workers in Japan, and that this rate rose precipitously after 10 years of work, reaching a prevalence of $66.7 \%$ after 20 years of work. Amin et al. ${ }^{15}$ found a prevalence of $68.85 \%$ for cervical lesions in workers exposed do acid mists in Jordan, and that this prevalence reached $91.80 \%$ when considering
Table 3. Mean nicotine dependence and alcohol use scores (SD) according to age group.

\begin{tabular}{lcccc}
\hline \multirow{2}{*}{ Age group } & \multicolumn{2}{c}{ Nicotine dependence } & \multicolumn{2}{c}{ Alcohol use } \\
\cline { 2 - 5 } & Mean & SD & Mean & SD \\
\hline 18-34 years & 0.68 & 1.79 & 2.73 & 3.14 \\
35-44 years & 1.89 & 3.27 & 3.13 & 4.5 \\
$>$ 44 years & 2.38 & 3.43 & 2.63 & 4.72 \\
$\mathrm{P}$ & \multicolumn{2}{c}{0.30} & \multicolumn{2}{c}{0.60} \\
\hline
\end{tabular}

tooth surface loss (not lesions, just loss of enamel surface characteristics), whereas, in controls, the prevalence of cervical lesions was $41.30 \%$ and that of tooth surface loss was $69.56 \%$. In a systematic review, Wiegand and Attin ${ }^{16}$ found that workers exposed to acid mists are at higher risk of dental erosion compared with controls, and that there are great prevalence variations in the literature, probably due to the multiplicity of study populations, working plants and countries. In our study, the overall prevalence of NCCLs was $76.84 \%$, being $86.04 \%$ in exposed workers and $68.51 \%$ in non-exposed workers. These values are higher than those found in international literature, when the presence of lesions is considered rather than the loss of enamel surface characteristics. The average time of employment in latest job for workers exposed to acid mists was approximately 8.6 years (CI 95\% 5.86-11.44), whereas for non-exposed workers 
it was 9 years (CI 95\% 6.35-11.75), which stresses the importance of time of exposure to acid mists at work. A reasonable explanation for these findings could be that a large number of companies in the city of Guarulhos, SP, Brazil, did not have a program to prevent environmental risks at work (PPRA) in place, implying that doses and time of exposure to acid mists could be higher than the permitted threshold limits provided by Brazilian federal law, thus affecting the prevalence of NCCLs.

In the 35-44 years age group, the Brazilian national oral survey found a mean root exposure rate of $10.59 \%$ (whether associated or not with NCCLs), ${ }_{1}^{13}$ whereas, in the present study, this age group had a $12.54 \%$ rate of NCCLs. The reason why the presence of NCCLs was higher than in the national survey (measured in terms of root exposure) was the high prevalence of subjects exposed to acid mists and chemical products (46\%) in the present study. National surveys show today that caries experience has been declining. The mean decayed component was 2.8 in 2003 versus 2.1 in 2010 among 12 year olds. The rate of missing teeth has also declined. In 2003, the mean number of missing teeth was $13.23^{10}$ in the $35-44$ years age group, but this value decreased to 7.48 in $2010 .{ }^{13}$ As a result, the deleterious effect of tooth wear is becoming more evident, as demonstrated by the dentin hypersensitivity rate of $46 \%$ and the high prevalence of NCCLs ${ }^{17}$ in the Brazilian population.

In agreement with previous investigations, ${ }^{4,5,14,15,16,1718}$ this study asserts that occupational factors, such as exposure to acid mists and chemical products, is an important contribution to the development of NCCLs, including dental erosion. The multifactorial origin of dental erosion has been accepted, but the relative contributions of the various processes remain unresolved. Lussi and Jaeggi ${ }^{6}$ have reported on the several aspects involved in the development of NCCLs, including buffering capacity and flow rates of saliva, $\mathrm{pH}$ decrease, and calcium and phosphate chelation mechanisms, but alcohol use, acidic drinks and food consumption, frequency and manner of tooth brushing, regurgitation, vomiting, drugs and occupation are also important factors to take into account. Occupational and environmental exposure to acid mists may also irritate soft tissue, resulting in periodontal changes, gingival recession and oral mucosa lesions. ${ }^{19}$ This exposure to acid mists over a long period of time (mean exposure time in the last occupational activity was approximately 9.5 years for the workers in this study) may lead to a chronic irritative process that will increase susceptibility to infections and, in the long run, promote salivary changes that contribute to the occurrence of NCCLs.

The abfraction theory, proposed by Lee and Eakle, ${ }^{20}$ has been posited to explain the formation of NCCLs. It is based on a biomechanical theory according to which tensile stress concentration at the cervical regions of teeth, caused by tooth flexure during heavy oclusal loading, leads to micro-crack formation cervically by disrupting bonds between hidroxyapatite crystals in enamel and dentin. Hur et al..$^{21}$ analyzed 50 teeth by micro-CT, with $3 \mathrm{D}$ reconstruction, and showed that the abfraction theory could not fully explain the

Table 4. Mean nicotine dependence scores (SD) in smokers, ex-smokers and non-smokers.

\begin{tabular}{|c|c|c|c|c|c|c|}
\hline & (n) & (\%) & Mean & SD & Mean cigarettes/day & SD cigarettes/day \\
\hline Smokers & 31 & 31 & 6.19 & 2.44 & 16.45 & 12.23 \\
\hline Ex-smokers & 23 & 23 & N/A & $\mathrm{N} / \mathrm{A}$ & N/A & $\mathrm{N} / \mathrm{A}$ \\
\hline Non-smokers & 46 & 46 & N/A & N/A & N/A & $\mathrm{N} / \mathrm{A}$ \\
\hline Fagerström index & (n) & (\%) & Mean & SD & Mean cigarettes/day & SD cigarettes/day \\
\hline Fagerström $=0$ & 69 & 69 & N/A & N/A & $\mathrm{N} / \mathrm{A}$ & $\mathrm{N} / \mathrm{A}$ \\
\hline Fagerström $>0$ & 31 & 31 & 6.19 & 2.44 & 16.45 & 12.23 \\
\hline Years of Smoking & (n) & $(\%)$ & Mean & SD & Mean cigarettes/day & SD cigarettes/day \\
\hline Never smoked & 46 & 46 & N/A & $\mathrm{N} / \mathrm{A}$ & N/A & N/A \\
\hline Smoked for under 15 years & 22 & 22 & 2.13 & 3.32 & 11.77 & 17.14 \\
\hline Smoked for over 15 years & 32 & 32 & 4.53 & 3.49 & 9.56 & 8.14 \\
\hline
\end{tabular}

N/A: Not applicable. 
formation of NCCLs because all teeth showed tissue loss above de cementoenamel junction, providing evidence for an abrasion theory for the development of NCCLs, with the involvement of other factors such as root exposure, tooth juxtaposition, gingival contour, toothbrush firmness and toothpaste abrasivity, along with the exposure of the cementoenamel junction to toothbrush bristles during oral hygiene.

This study showed that age group and occupational factors were significantly associated with the presence

Table 5. Mean scores (SD) of alcohol dependence according to AUDIT categories.

\begin{tabular}{lcccc}
\hline Audit & Mean & SD & (n) & (\%) \\
\hline Low (0 to 7) & 1.44 & 2.15 & 88 & 88 \\
Moderate (8 to 15) & 11.5 & 1.9 & 10 & 10 \\
High (16 to 19) & 17 & N/A & 1 & 1 \\
Probably (20 to 37) & 21 & N/A & 1 & 1 \\
Audit $=0$ & & & & \\
Audit $>0$ & 0 & N/A & 56 & 56 \\
\hline
\end{tabular}

of NCCLs, as demonstrated by unconditional logistic regression. On the other hand, upon applying multiple linear regression, the number of NCCLs was found to be significantly associated with years of smoking and age group, although the $\mathrm{r}^{2} \mathrm{a}$ (adjusted $\mathrm{r}$ square) indicated that only $19.8 \%$ of the variation in the number of lesions was explained by the variables present in this regression model. This observation seems to support a multifactorial process in the development of NCCLs, with no clearly dominant factor. These findings are biologically plausible, in that we know that tobacco use can lead to gingival recession, ${ }^{22}$ and thus contribute to the development of NCCLs, as supported by the abrasivity theory. ${ }^{21}$

Exposure to acid mists has already been reported to be a risk factor for oral mucosa lesions among workers without lip sealing because this increases the intensity of acid mist exposure in the mouth. ${ }^{23}$ We believe that using the protection of personal equipment (namely masks) could prevent the action of acids in the oral cavity of workers, independently of

Table 6. Association of tobacco use with DMFT and NCCLs.

\begin{tabular}{lcccccccc}
\hline & $(\mathrm{n})$ & DMFT & $\mathrm{D}$ & $\mathrm{M}$ & $\mathrm{F}$ & $\mathrm{NCCL}$ & $\% \mathrm{NCCL}$ & $\mathrm{Age}(\mathrm{mean})$ \\
\hline Fagerström $=0$ & 69 & 14.86 & 2.10 & 7.60 & 4.72 & 3.14 & 16.86 & 43.30 \\
Fagerström $>0$ & 31 & 18.55 & 2.22 & 12.87 & 3.22 & 4 & 25.20 & 46.03 \\
$\mathrm{p}$ & & 0.01 & 0.81 & 0.002 & 0.1 & 0.32 & 0.09 & 0.22 \\
Non-smoker & 46 & 13.63 & 2.21 & 6.26 & 4.84 & 2.34 & 10.90 & 40.15 \\
$<15$ years of smoking & 22 & 18.31 & 2.04 & 11.81 & 4.13 & 2.31 & 18.66 & 45.36 \\
$>15$ years of smoking & 32 & 17.84 & 2.09 & 11.75 & 3.5 & 5.68 & 32.26 & 49.06 \\
$\mathrm{p}$ & & 0.009 & 0.95 & 0.003 & 0.61 & 0.0006 & 0.0003 & 0.008 \\
\hline
\end{tabular}

Table 7. Multiple linear regression analysis of the number of NCCLs.

\begin{tabular}{|c|c|c|c|c|c|}
\hline & Variables final model & $\beta$ & $\mathrm{Cl} 95 \% \beta$ & p-model & $r^{2} \alpha$ \\
\hline 1 & Schooling a & -0.041 & $(-0.842 a 0.562)$ & 0.693 & 0.198 \\
\hline 2 & Occupational exposure ${ }^{b}$ & -0.148 & $(-2.696$ a 0.310$)$ & 0.11 & \\
\hline 3 & Years of smoking ${ }^{c}$ & 0.373 & $(0.029$ a 0.211$)$ & 0.011 & \\
\hline 4 & Nicotine dependence ${ }^{d}$ & -0.038 & $(-0.424$ a 0.321$)$ & 0.785 & \\
\hline 5 & Alcohol use e & -0.088 & $(-0.272$ a 0.109$)$ & 0.397 & \\
\hline 6 & Age group ${ }^{f}$ & 0.215 & $(0.050$ a 2.165$)$ & 0.040 & \\
\hline
\end{tabular}

$\mathrm{p}$-model $=0.000$

aAbove middle school $=0$; under middle school $=1$.

bexposure to acid mists $=1$; non-exposure $=0$.

cNumber of years of smoking.

dFagerström questionnaire score.

eAUDIT questionnaire score.

${ }^{\dagger} 18-34$ years age group $=0 ; 35-44$ age group $=1 ;>44$ years $=2$. 
Table 8. Unconditional logistic regression analysis of the presence of NCCLs.

\begin{tabular}{|c|c|c|c|}
\hline Variables final model & OR & $\mathrm{Cl} 95 \%$ & $p$ \\
\hline Age group ${ }^{a}$ & 4.04 & 1.77 to 9.22 & 0.0009 \\
\hline Tobacco use ${ }^{b}$ & 1.73 & 0.49 to 6.17 & 0.39 \\
\hline Schooling ${ }^{c}$ & 1.57 & 0.43 to 5.75 & 0.49 \\
\hline Alcohol use ${ }^{d}$ & 1.23 & 0.37 to 4.05 & 0.73 \\
\hline Occupational exposure ${ }^{e}$ & 3.84 & 1.10 to 13.49 & 0.03 \\
\hline \multicolumn{4}{|c|}{ 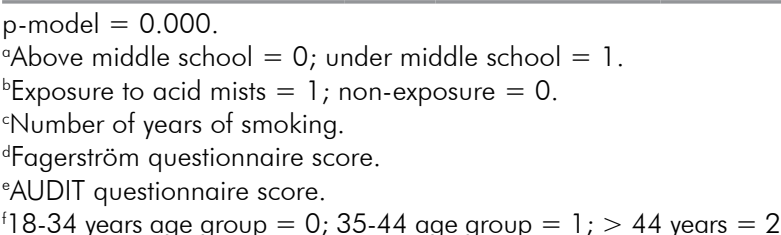 } \\
\hline
\end{tabular}

lip sealing. Almeida et al. ${ }^{23}$ have reported periodontal attachment loss $(>4 \mathrm{~mm}$ ) in workers exposed to acid mists, independently of age, alcohol consumption, and smoking habit, but these findings were limited to workers who did not use dental floss.

Because $88 \%$ of workers showed a low dependence on alcohol consumption in the present study, the association between this factor and NCCLs lost strength, but we should not discard future studies to further investigate potential associations between alcohol consumption and oral health.

The prevalence of NCCLs in this Brazilian population of workers was high, suggesting that it is a relatively common condition, especially among workers exposed to acid mists and chemical products. Furthermore, we agree with a multifactorial theory for the development of NCCLs, as proposed by others. $16,20,21,22,23$

In a systematic review, Wiegand and Attin ${ }^{16}$ observed dental erosion in workers, even when the threshold limit values of exposure to acid mists were observed by companies. It may be the case that these dose and exposure-time threshold limits are unable to guarantee the oral health conditions of workers, thus indicating that further epidemiological investigations in this field are still needed to implement educative, preventive and oral health promotion strategies.

One limitation of this study is that we divided workers according to job characteristics through occupational anamneses. The division was made between workers exposed to acid mists (electroplating and metallurgical plants, welders, cleaners and those working in product recycling) and those non-exposed to acid mists (tailors, drivers, gardeners, masons, carpenters, musicians, cooks and those working in administrative services). Because some companies failed to have a PPRA in place, we were unable to assess doses and time of exposure (hours per day) to acid mists, and this information could be useful to better explain the formation of NCCLs.

Our investigation can potentially explain $20 \%$ of the risk factors for NCCLs, as demonstrated by multiple linear regression, and was adjusted for tobacco use and alcohol consumption. Nevertheless, future studies are warranted using other analyses, including those that focus on factors related to occlusal loading, quality of food intake and tooth brushing forces during oral hygiene, which were not accounted for in this epidemiological investigation.

\section{Conclusion}

The prevalence of NCCLs was particularly high in the group of workers examined in this study, and the risk factors involved were age, exposure to acid mists and smoking habit. Companies are urged to monitor Brazilian workers' oral health through periodical clinical examinations, and to ensure the use of personal protection equipment and implement strategies to reduce tobacco use, in order to improve the oral health status of their employees. 


\section{References}

1. World Health Organization. Occupational exposure to mists and vapours from strong inorganic acids and other industrial chemicals. Lyon: Monographis; 2008. IARC; p. 243.

2. Aw TC, Lepe X, Johnson GH, Mancl L. Charasteristics of non carious cervical lesions: a clinical investigation. J Am Dent Assoc. 2002 Jun;133(6):725-33.

3. Levitch LC, Bader JD, Shugars DA, Heymann HO. Non carious cervical lesions. J Dent. 1994 Aug;22(4):195-207.

4. Tuominen LM, Tuominen RJ, Fubusa F, Mgalula N. Tooth surface loss and exposure to organic and inorganic acid fumes in workplace air. Community Dent Oral Epidemiol. 1991 Aug;19(4):217-20.

5. Chikte U, Josie-Perez AM, Cohen TL. A rapid epidemiological assessment of dental erosion to assist in settling an industrial dispute. J Dent Assoc S Afr. 1998 Jan;53(1):7-12.

6. Lussi A, Jaeggi T. Erosion - diagnosis and risk factors. Clin Oral Investig. 2008 Mar;12 Suppl 1:S5-13. doi: 10.1007/s00784-007-0179-z.

7. Kinane DE. Causation and pathogenesis of periodontal diseases. Periodontol 2000. 2001;25:8-20.

8. Wiegand A, Burkhard JPM, Eggmann F, Attin T. Brushing force of manual and sonic toothbrushes affects dental hard tissue abrasion. Clin Oral Investig. 2013 Apr;17(3):815-22. doi: 10.1007/s00784-012-0788-z.

9. Antunes JLF, Peres, MA. Epidemiologia da saúde bucal. São Paulo: Editora Guanabara Koogan; 2006.

10. Brasil. Ministério da Saúde. Condições de Saúde Bucal da população Brasileira. 2002-2003 [Internet]. Ministério da Saúde. Resultados principais. [cited 2013 Jul 23]. Available from: http://dtr2001.saude.gov.br/editora/produtos/livros/ pdf/05_0053_M.pdf

11. World Health Organization. Management of substance dependence. Screening and brief intervation. Geneva: WHO; 2003.

12. Heatherthon TF, Kozlowsky LT, Frecker RC, Fagerström KO. The Fagerström test for nicotine dependence: a revision of the Fagerström tolerance questionnaire. Br J Addict. 1991 Sep;86(9):1119-27.
13. Brasil. Ministério da Saúde. Projeto SB Brasil 2010: pesquisa nacional de Saúde Bucal [Internet]: Ministério da Saúde. Resultados principais. [cited 2013 Jul 23]. Available from: http://dab.saude.gov.br/cnsb/sbbrasil/arquivos/projeto_ sb2010_relatorio_final.pdf

14. Suyama Y, Takaku S, Okawa Y, Matsukubo T. Dental erosion in workers exposed to sulfuric acid in lead storage battery manufactoring facility. Bull Tokyo Dental Coll. 2010;51(2):77-83.

15. Amin WM, AL-Omouush SA, Hattab FN. Oral health status of workers exposed to acid fumes in phosphate and battery industries in Jordan. Int Dent J. 2001 Jun;51(3):169-74.

16. Wiegand A, Attin T. Occupational dental erosion from exposure to acids-a review. Occup Med (Lond). 2007 May;57(3):169-76.

17. Scaramucci T, Anfe TEA, Ferreira SS, Frias AC, Sobral MAP. Investigation of prevalence, clinical features, and risk factors of dentin hypersensitivity in a selected brazilian population. Clin Oral Investig. 2014;18(2):651-7. doi: 10.1007/s00784-013-1008-1. Epub 2013 Jun 6.

18. Lie T, Due NA, Abrahamsen B, Boe OE. Periodontal health in a group of industrial employees. Community Dent Oral Epidemiol. 1988 Feb;16(1):42-6.

19. Vianna MIP, Santana VS, Mckelvey W. Periodontal health and oral mucosa lesions as related to occupational exposure to acid mists. Community Dent Oral Epidemiol. 2005 Oct;33(5):341-8.

20. Lee WC, Eakle WS. Possible role of tensile stress in etiology of cervical erosive lesions of teeth J Prosthet Dent. 1984 Sep;52(3):374-80.

21. Hur B, Kim HC, Park JK, Versluis A. Caracteristics of non carious cervical lesions - an ex-vivo study using micro computed tomography. J Oral Rehabil. 2011 Jun;38(6):469-74.

22. Warnakulasuriya S, Dietrich T, Bornstein MM, Casals Peidró E, Preshaw PM, Walter C, et al. Oral health risks of tobacco use and effects of cessation. Int Dent J. 2010 Feb;60(1):7-30.

23. Almeida TF, Vianna MIP, Santana VS, Gomes Filho IS. Occupational exposure to acid mists and periodontal attachment loss. Cad Saude Publica. 2008 Mar;24(3):495-502. 